\title{
Renewing the City through Public Participation and Cultural Activities. The Case Study of Gillet Square, a Community-Led Urban Regeneration Project.
}

\section{ABSTRACT}

This article focuses its attention on inner cities and asks questions about their possible redevelopment. How can an urban regeneration project improve its social innovation effects? We argue that community-led enterprises with social values can drastically improve social innovation in urban regeneration. This article presents the main features of Gillet Square, a project promoted by Hackney Co-operative Developments, a Community Interest Company based in London East End. The nature of the research is qualitative, findings show how a community-led initiative can involve local stakeholders, develop new local assets for and promote social cohesion and inclusion.

\section{KEY-WORDS}

COMMUNITY INTEREST COMPANY, URBAN REGENERATION, SOCIAL INNOVATION, CITIZENS' ENGAGEMENT 


\section{Introduction}

Urban systems are in constant evolution and their attributes shift due to the correlations between internal and external forces. For decades, scholars in different fields have considered how neighbourhoods react to dramatic economic changes and the role played by governments, the private sector and civil society in the conversion and renewal of these zones (Glass and Westergaard, 1965; Colquhoun, 1995; Jones and Evans, 2008; Vicari Haddock and Moulaert, 2009; Porter and Shaw, 2013). Increasing civil engagement in urban planning and the key role played by community-led organisations are the main factors in these renewal processes. The involvement of different stakeholders, for local socio-economic renewal, is more critical than ever. They can call to action wide social networks in the communities interested in renewal projects. The mix between top-down policies that enable communities to selforganise their local services, and the bottom-up experiences of community-led organisations, is now presenting interesting results in term of social innovation in inner cities. The former see in civil society a key partner in the development of new opportunities for neighbourhoods, the latter are supported by national policies in fostering new services and resources in their communities. The aim is the recovery of disadvantaged urban areas through economic growth and better social conditions. The final output of this process of interactions between the national and local levels is the creation of community-led enterprises, which can continuously manage assets and projects for people's wellbeing; citizens form these new enterprises that work in embedded social structures, involve different stakeholders and have a clear mission forward for the community (Peredo and Chrisman, 2006).

The hypothesis is that the peculiar structure of the community-led organisations, which involves local stakeholders, interest groups, and private and public organisations, is the key factor that generates social innovation in urban regeneration. In the case study, this paper identifies practices that foster new solutions for critical social problems through the sustainable and inclusive regeneration of an inner city. Barton, Grant and Guise (2003) claimed that the more the local community is involved in the design and development of neighbourhood renewal, the greater the likelihood is that they will create a place that has local relevance. Frey (1999) noted that people in a neighbourhood are more responsible and connected if they have been involved in shaping their own places. Moreover, Eizaguirre and Parés (2018) point out that research needs an agency-based explanation for social innovative initiatives.

We assume that community enterprises play a strategic role in urban regeneration processes, which are not simply a renewal of physical conditions but a wider intervention into the social and economic aspects inside neighbourhoods (Jones and Evans, 2008; Vicari Haddock and Moulaert, 2009); thus, the processes need to promote valuable initiatives in urban regeneration and this research aims to understand the specific dynamics that permit these improvements. The research question that arises from these considerations is how does a community-led enterprise operate for social innovation in urban regeneration involving the local community? Moulaert et al. (2003; 2010; 2013) theorise social innovation as the practices for innovative solutions to a range of problems which affect people such as exclusion, deprivation, poverty, and lack of wellbeing. This process 
involves many actors and it fosters inclusion and wellbeing through the implementation of social relations and conditions. Social innovation can trigger changes in the human condition, needs satisfaction, access to resources, and the rebalance of power between citizens and governments.

Sustainable and inclusive urban regeneration has been part of the international debate regarding urban structure and community leadership, due to its relevance in urban dynamics which could foster a classist re-design of neighbourhoods (Jones and Evans, 2008; Vicari Haddock and Moulaert, 2009; Parés, Ospine and Subirats, 2017; Eizaguirre and Parés, 2018). This paper analyses an English case study, Gillet Square, a project promoted by Hackney Co-operative Developments (HCD), a Community Interest Company (CIC) — that is an English legal form for community-focus businesses_-based in London's East End. The descriptive analysis is carried out with a qualitative approach through semistructured interviews with the Gillet Square manager and the former HCD CEO, who led the entire renewal project. The assessment of the Gillet Square impact is also possible through an analysis of reports and evaluations from partner organisations involved in this project. Evidence comes from the narration of Gillet Square history and the daily work with other organisations involved; moreover, the partners' assessments of this project provide information on Gillet Square planning activities and collaboration for a better understanding of Hackney criticisms. These results are assessed in terms of local wellbeing and social cohesion; the findings support policymakers and academics who promote a more inclusive and community-led urban regeneration. The descriptive approach is useful to investigate how HCD builds local networks and fosters social innovation in the urban regeneration process of Hackney. This paper questions the results that HCD has achieved during these years and its impact on the neighbourhood. Moreover, the investigation inquiries the modalities through which this CIC has developed its local community development process, considering HCD partners' point of view on the enterprise commitment toward the Hackney community.

Section 2 of this paper presents the English policy framework and how the top-down interventions are supporting the promotion of local activation for community empowerment and local assets management. Section 3 presents the main information about the London Borough of Hackney and explains the main social problems observed in this area. Section 4 illustrates the Gillet Square project and the main features of Hackney Co-operative Development. In the end, the discussion and conclusion highlight how the case study elements can contribute to improving social innovation in urban regeneration and local services through a combination of national policy and local engagement.

\section{Urban regeneration in England and the Community Interest Companies (CICs)}

Urban regeneration is a set of specific policies aiming to model cities in order to make their physical aspect fit in the role assigned in a specific historical moment (Couch, Fraser and Percy, 2003; Jones and Evans, 2008; Tallon, 2010). This involves many elements such as physical conditions, social needs, economic development and environmental sustainability (Roberts, Sykes and Granger, 2016). The politics involved in shaping the framework that supports urban regeneration processes 
has to address renewal toward a specific idea of city and development; this policy framework involves different fields because the renewal of cities implies huge interventions on different aspects that are intrinsically correlated. Housing, welfare, economic development, transportation, health, environment are main issues in urban regeneration (Tallon, 2010).

Figure 1. The urban regeneration policy mix

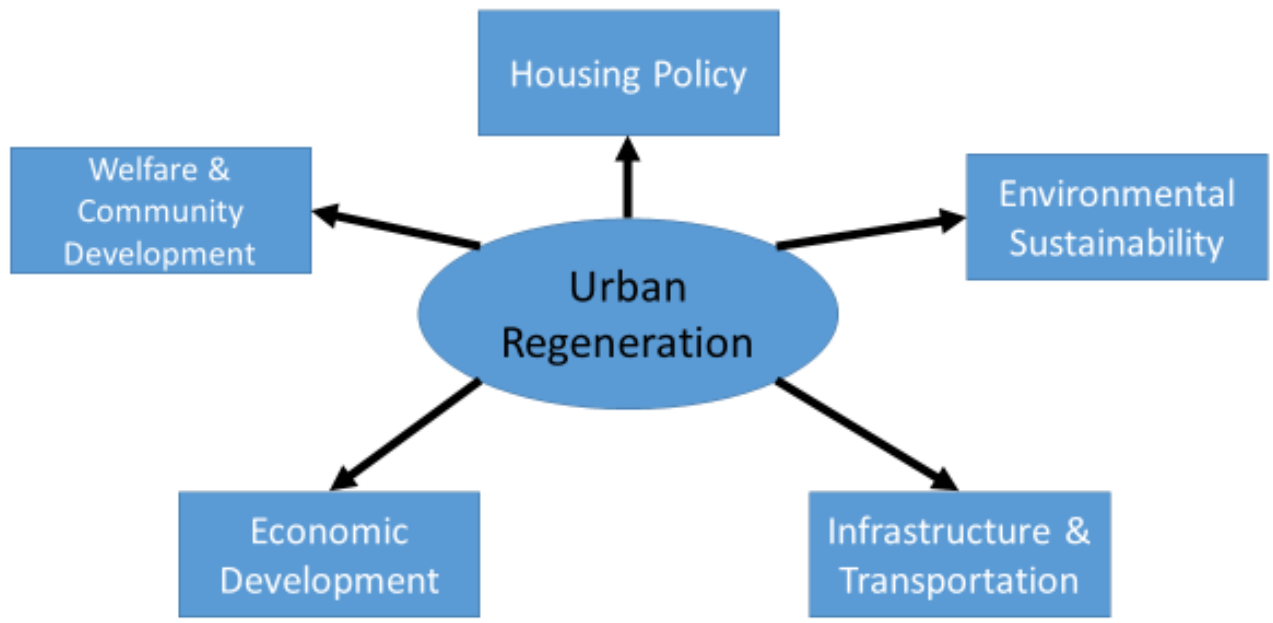

Source: Author's elaboration

The neoliberal agenda has deeply influenced English governance; from Thatcher's government to the "Big Society Agenda", elaborated upon by Cameron, passing through Blair's premiership, English urban regeneration has paid particular attention to the devolution of assets and responsibilities to local authorities and community organisations (Couch, Fraser and Percy, 2003; Jones and Evans, 2008; Verhage, 2005; Vicari Haddock and Moulaert, 2009; Swyngedouw, Moulaert and Rodriguez, 2012).

This political approach aims to give more influence to non-state actors in delivering services, driving the socio-economic development and improving community-led regeneration (DCLG, 2011; 2012; Deas, 2013; Varady, Kleinhans and Van Ham, 2015). The Localism Act (2011) works in this direction and allows local councils and communities to shape their socio-economic development (Lawless, 2011; Deas, 2013). The strengthening of bottom-up initiatives, free from old public topdown schemes (typically an expression of a former governance idea) should lead to the formulation of tailored local regeneration strategies developed by local actors. One of the main innovations in the Localism Act is the "community right to bid". This provides communities with the right to list a building or a land as "community asset value". When a listed asset is to be sold, local community groups will, in many cases, have a fairer chance to make a bid to buy it on the open market. 
This asset transfer is a key element in the growth of the community enterprise sector, and the English government has promoted many policies for the devolution of these assets (Jones and Evans, 2008). This process supports the organisations with stable assets for their activities and, in many cases, promotes their regeneration. The report about asset transfers delivered by the Department for Communities and Local Government (DCLG) in 2007 proposed the creation of the Asset Transfer Unit that is in charge of managing the process of acquisition of under-used land and abandoned buildings from the public sector to community organisations. The Community Asset Fund (30 million GBP) provided organisations with financial support for these acquisitions (DCLG, 2007).

An important step in the devolution reform has been the innovative legal form of Community Interest Company (CIC). With the Community Benefit Society, this legal form enables local groups of citizens to take direct action in the local economy. It is possible to consider community enterprises as a sub-group in the social enterprise universe. Pearce (2003) identifies the main characteristics of social enterprises: social purposes, not distributing profits, holding assets and engaging in trade on the open market, democratic involvement of members and independent government. In addition, community enterprises define their objectives in relation to a clear geographical population (Bailey, 2012). The services they provide people with vary among places, but these tend to be the provision of housing, workplace training, health services, sport facilities, social services, cultural and linguistic integration of immigrants and nursery services (Bailey, 2012; Varady, Kleinhans and Van Ham, 2015).

In 2006, the English government introduced the CIC; it can be applicable to companies limited by guarantees or shares whose mission is the interest and benefit of the community. It can prove this through the Community Interest Test, which assesses the validity of the community benefit. CICs use local assets, public or private, to run businesses. The English legislation prevents the use of these assets for private purposes through the "asset lock". This ensures that the assets are used for community benefit and in case of company dissolution, these assets have to be transferred to another CIC continuing the community work. Moreover, CICs have to ensure the engagement of local stakeholders in the decision making process. This allows for a wider perception of the local needs and potentialities.

This policy framework is the result of the collaboration between the English Government and Locality, the national network of community-led organisations. This organisation support thousands of members in the UK and it has become the main referent for the government in the field of community development. It has collaborated in the creation of legislation for the improvement of community-led organisations. This partnership has produced many results such as the program Our Place (2013-2015) for the re-organisation of local services in 120 neighbourhoods. This program transferred competences, resources and assets from the public sector to community enterprises and organisations. Locality had a key role in this transition supporting the organisations in the management and improvement of the services. The aim was not only cost reduction but also the involvement of local citizens and organisations into an innovative model of local governance (Tricarico and Zandonai, 2018). 
To sum up, the communities' opinions and needs are the central core of this new renewal approach. The government allows taking direct control of local planning and assets in order to tailor the right solution for each place. The CIC legal framework permits local groups to create new businesses and generate services and resource for their communities. The next sections present the main social problems in Hackney and how HCD, networking with local stakeholders, is generating social innovation with the provision of local services and renewal projects.

\section{The London borough of Hackney}

Hackney is officially a part of East London. From the end of the 18th century, the borough was known as an important development and industrial zone. The Hackney setting presents a critical situation correlated to its structural necessity of reconversion. Since the 1980s, Hackney has been known for its dramatic social situations and the urban policies adopted in recent years have not resolved its socio-economic problems. This section illustrates the main features of Hackney social conditions. Public authorities and the third sector work on these issues every day, and the collaboration among different organisations helps to implement solutions for local needs.

Figure 2. Hackney in the Great London area

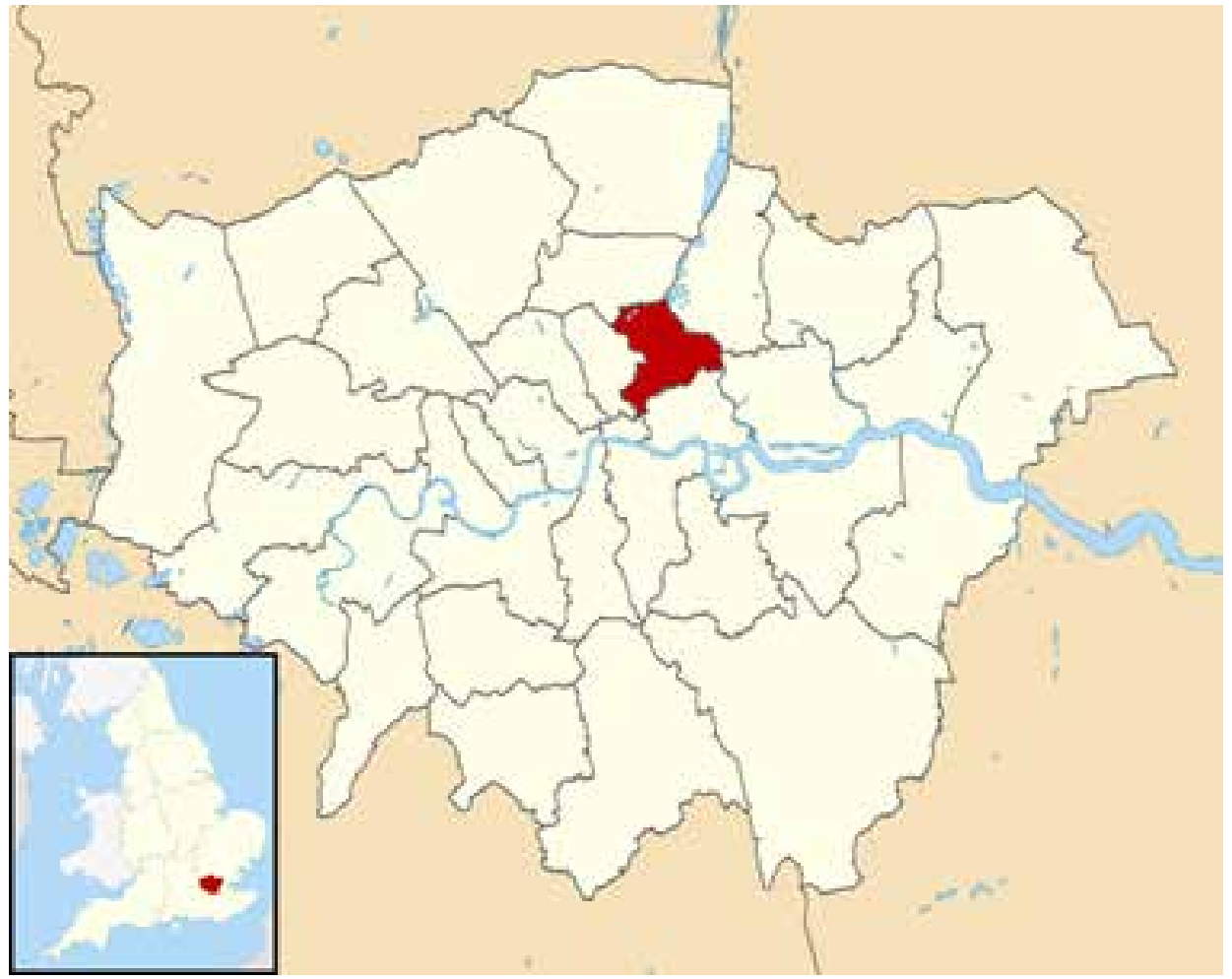

Source: Wikipedia 
During the second half of the 19th century, Hackney's population grew rapidly as estates and farmlands were built upon it. The rapid changes, which occurred during the Victorian era, were due to the development of factories and the building of new houses for the working class.

The historical analysis of the population of this borough is interesting. From the beginnings of the 19th century, industrialization drove an enlargement of the area. From 1801 to 1901, the rate of growth was $2,460 \%$, from 14,609 to 374,132 people. This increase was constant until the 1920 s. However, from 1921 to 1981 , the last year with a negative growth rate, the population decreased by $51 \%$, from 368,469 to 179,536 . This was likely due to the destruction from the war, the closure of industries and the economic crisis of the 1970s and the 1980s. According to Nomis (2017) ${ }^{1}$, from 1991 to the present, the population of Hackney has started to grow again and the rate has increased by $37 \%$. Hackney's current population is estimated at 269,009 people (Hackney Council, 2017). This demographic analysis is correlated with the urban evolution of this borough because the highest level of population during the 19th and 20th centuries had left a number of buildings that now require a new scope. During the 20th century, an inverse trend characterised the evolution of British cities, in particular the reconstruction after World War I. Increased mobility led the middle class to move outside the traditional Victorian areas and determined an urbanisation of peripheral areas where land was cheaper. This determined the definition of "inner cities" as those areas, formerly industrial, placed in the 19th urban structure of cities (Colquhoun, 1995; Home, 2013).

Hackney is a typical British inner city, an area strongly developed during the industrial area where factories and working-class houses were side by side; massive production required huge infrastructures thus multi-storey mills for the textile and other industries, docks, and warehouses occupied great portions of cities.

As with many other inner cities, Hackney has suffered the process of deindustrialisation from the end of 1970s to the present. In the 2015, it was the eleventh most deprived local authority overall in England according to the Index of Multiple Deprivation ${ }^{2}$. In 2015, 17\% of its Lower Super Output Areas were in the top ten percent most deprived, compared with 42\% in 2010 (Hackney Council, 2017). Deprivation is linked to poorer health outcomes, which are derived from a wide range of factors such as smoking, unhealthy eating and physical inactivity. A quarter of adults in Hackney are inactive, i.e. do less than half an hour of moderate activity a week (A5scend, 2016). Hackney also has one of the highest rates of child poverty, according to End Child Poverty Campaign, with 37\% (data from 2015, last year available) of children living in poverty based on disposable income after housing costs have been deducted (Hackney Council, 2017). This value is almost double the rate for England (20.1\%) and significantly higher than the London average (26.7\%).

Table 1 presents the percentages of unemployment in Hackney, London and England. The numbers clearly show how the borough strongly suffers a more critical situation compared with the metropolis and the country.

The Official Labour Market Statistics.

2 In 2010, it was ranked second. 
Table 1. Unemployment in Hackney, London and England (\%)

\begin{tabular}{c|c|c|c}
\hline & Hackney & London & England \\
\hline 2007 & 11.4 & 6.9 & 5.2 \\
\hline 2008 & 9 & 7 & 7.7 \\
\hline 2009 & 11 & 9.2 & 7.6 \\
\hline 2011 & 10.4 & 8.9 & 8 \\
\hline 2012 & 10.7 & 9.5 & 7.9 \\
\hline 2013 & 10.7 & 9.2 & 7.5 \\
\hline 2014 & 11 & 8.7 & 6.2 \\
\hline 2015 & 8.1 & 7 & 5.2 \\
\hline 2016 & 6.9 & 6.1 & 4.8 \\
\hline 2017 & 7.2 & 5.7 & 4.4. \\
\hline
\end{tabular}

Source: Nomis (2018).

During the last decade, steady economic growth, due to the proliferation of creative and technological enterprises, has brought a great deal of attention to this neighbourhood (Porter and Shaw, 2009). Table 2 shows the historical evolution of enterprise population in Hackney in recent years. Figures confirm the increase in business activities, in particular small and medium rather than large firms such as in the past. "Over the past decade, Hackney's old factories have become workspaces for a new boom in technology, media, and telecommunications, or more broadly, knowledge-based industries. Hackney is home to the centre of one of the largest clusters of knowledge industries in Europe." (Hackney Council, 2015: 3).

Hackney is living a deep change in its social structure and urban outlook, modifying its status from an old and abandoned borough to a gentrified zone of London. The recent success of Hackney is due to the Olympic games of 2012 in the nearby new part of East London. The opening of the East London underground in 2012 has led the gentrification process close to the Dalston and Bethnal Green areas (Porter and Shaw, 2009). 
Table 2. Historical evolution of Hackney enterprises

\begin{tabular}{c|c|c|c|c}
\hline Year & $\begin{array}{c}\text { Micro } \\
(\mathbf{0 - 9} \text { workers })\end{array}$ & $\begin{array}{c}\text { Small } \\
(\mathbf{1 0 - 4 9} \text { workers })\end{array}$ & $\begin{array}{c}\text { Medium } \\
(\mathbf{5 0 - 2 4 9} \text { workers })\end{array}$ & $\begin{array}{c}\text { Large } \\
(\mathbf{2 5 0} \text { workers })\end{array}$ \\
\hline 2010 & 8,460 & 715 & 135 & 30 \\
\hline 2011 & 8,765 & 715 & 135 & 30 \\
\hline 2012 & 9.665 & 865 & 150 & 30 \\
\hline 2013 & 10,185 & 995 & 165 & 30 \\
\hline 2014 & 11,560 & 1,050 & 185 & 40 \\
\hline 2016 & 13,295 & 1,205 & 190 & 40 \\
\hline 2017 & 15,360 & 1,295 & 195 & 35 \\
\hline
\end{tabular}

Source: Nomis (2018).

Nevertheless, new businesses are not a sufficient solution for the decrease of the disadvantage situations in this area. In his report for the Centre for Analysis on Social Exclusion of the London School of Economics, Fenton (2016) underlines the historical investigation of poverty distribution in the 2000s, which can explain the social changes in East London in general and Hackney in particular. The renewal of a wide share of houses and the consequent increase in prices have pushed many low-income families to other cheaper boroughs outside Inner London. This means that the social improvement recorded in these years are not an improvement of former dwellers' social conditions, but a displacement of them (Fenton, 2016).

Crosschecking the data from Super Outputs Areas, the result is that in the poorest areas of Hackney, $17 \%$ of super output areas (Hackney Council, 2017), the level of ethnic diversity is higher. Table 3 shows the ethnic composition of the areas which are in the 10th percentile of the highest deprived in England compared with the overall percentage of Hackney. This means a link between the most difficult situations in the borough and ethnic minorities, which represents an important issue in the analysis on the necessary social work in this neighbourhood. It proves that the HCD's work for local minorities has good reasons, in particular the work with the Black African/British/Caribbean community. 
Table 3. Ethnic composition of the poorest LSOAs in Hackney (\%)

\begin{tabular}{|c|c|c|c|c|c|}
\hline LSOA & White & $\begin{array}{l}\text { Mixed multiple } \\
\text { ethnic groups }\end{array}$ & $\begin{array}{c}\text { Asian/Asian } \\
\text { British }\end{array}$ & $\begin{array}{c}\text { Black/African/ } \\
\text { Caribbean/Black } \\
\text { British }\end{array}$ & $\begin{array}{c}\text { Other ethnic } \\
\text { groups }\end{array}$ \\
\hline $002 \mathrm{~A}$ & 49.7 & 6.4 & 11.6 & 26 & 6.3 \\
\hline $002 \mathrm{D}$ & 43.1 & 6.1 & 13.4 & 30.1 & 7.3 \\
\hline $002 \mathrm{E}$ & 41.2 & 7.4 & 13.8 & 29 & 8.6 \\
\hline $002 \mathrm{~F}$ & 40 & 8.3 & 11.2 & 31.3 & 9.2 \\
\hline 010B & 31.2 & 8.6 & 14.9 & 40.2 & 5.1 \\
\hline $013 \mathrm{~A}$ & 26.8 & 6.2 & 8.6 & 54 & 4.4 \\
\hline 013B & 38 & 5.7 & 7.8 & 41.2 & 7.3 \\
\hline $013 \mathrm{C}$ & 34.1 & 6.9 & 11.2 & 43.1 & 4.7 \\
\hline $014 \mathrm{~A}$ & 40.9 & 6.8 & 12.6 & 31.1 & 8.6 \\
\hline $018 \mathrm{~A}$ & 42.8 & 5.7 & 9.9 & 38.5 & 3.1 \\
\hline 018B & 48.6 & 8.6 & 10.9 & 28.8 & 3.1 \\
\hline 019A & 33.5 & 8.9 & 11.6 & 42.6 & 3.4 \\
\hline 019C & 34.8 & 7.6 & 10.8 & 41.6 & 5.2 \\
\hline 019F & 30.1 & 6.6 & 10.3 & 47.3 & 5.7 \\
\hline $022 \mathrm{~B}$ & 45.3 & 5.5 & 13 & 32.9 & 3.3 \\
\hline $023 \mathrm{C}$ & 60.5 & 8.1 & 8.9 & 17.6 & 4.9 \\
\hline $024 \mathrm{~A}$ & 36 & 7.2 & 12.8 & 38.8 & 5.2 \\
\hline $024 \mathrm{~F}$ & 45.8 & 7.3 & 7.3 & 33.2 & 6.4 \\
\hline $026 \mathrm{~B}$ & 53.5 & 6.7 & 10.9 & 23.6 & 5.3 \\
\hline $028 \mathrm{~A}$ & 34.1 & 8.2 & 19.3 & 31.6 & 6.8 \\
\hline $029 \mathrm{C}$ & 42 & 6.1 & 13.7 & 28.9 & 9.3 \\
\hline Average & 4.6 & 7 & 11.6 & 34.8 & 5.9 \\
\hline Hackney & 54.7 & 6.4 & 10.5 & 23.1 & 5.3 \\
\hline
\end{tabular}

Source: ONS (2018). 
As the analysis shows, Hackey presents radical socio-economic issues and this requires significant initiatives for tackle them down; HCD is a leader in the social and solidarity economy in Hackney and has develop many project which address solutions for the social problems listed above. In 2016, HCD commissioned an independent external evaluation of the Gillet Square project on the 10th anniversary of the square's launch. A5cent was the agency in charge of this assessment. This work was based on surveys and interviews with the Gillet Square working group, HCD-run consultation focus groups and other organisations' reports on the square's activities. This work shows the main issues regarding the zone of Dalston, where Gillet Square is situated. This place is in line with the index of deprivation of Hackney. Dalston has the smallest amount of public green space in the borough (Hackney Council, 2007) and many local families live in flats lacking access to decent outdoor environments. The desire for more free or low-cost activities is correlated to the need for socialisation. In many cases, this is obstructed by the fear of anti-social behaviours which are perceived by many residents as a terrible issue. A focus group with older women at Age UK's Agewell group in 2016 found that drinking and threatening behaviour in the square were issues for them. Moreover, Dalston is the ward with the highest rate of crime and disorder problems (A5cent, 2016). Figure 3 shows people's (participants into Gillet Square activities) concerns about Dalston. It is relevant to underline the high worry about local disempowerment.

Figure 3. Frequencies (\%) of those who consider the following to be problems in Dalston

\section{Low community spirit}

Poor access to decision-making about the use of outdoor space

Privđisation of public amenties

Local residents disempowered in the face of rapid change

- \% Agree strongly

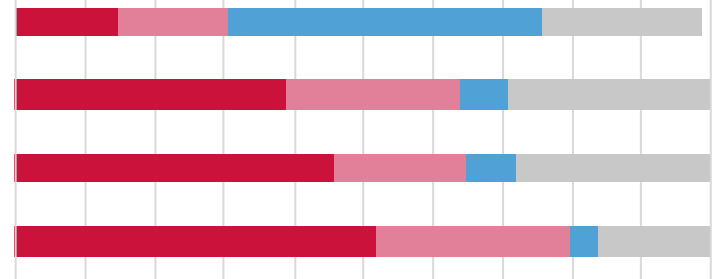

$\begin{array}{lllllllllll}0 & 10 & 20 & 30 & 40 & 50 & 60 & 70 & 80 & 90 & 100\end{array}$

Source: A5cent Survey (2016).

The analysis presents the main social problems in Hackney with a particular focus on Dalston; what emerges here is a structural necessity of urban regeneration and re-planning of Hackney scope and role for its economy. The neighbourhood has a huge portfolio of assets in re-use and the new economy is triggering reconversion processes that can impact in a negative way this part of London. The next section presents the HCD main features and how this community enterprise is working for a community-focused renewal of Hackney assets, adopting a social and inclusive approach for its activities and implementing solutions that target specific Hackney problems such as unemployment, social isolation, and absence of social venues. 


\section{The Hackney Co-operative Development and Gillet Square project}

The Hackney Co-operative Development is a Community Interest Company specialised in business support, customised training, affordable workspace provision and creation of suitable environments for small businesses, community groups and voluntary organisations in Hackney. Established in 1982, the HCD has deep roots in the cooperative movement of London. The Hackney House Cooperative set up this organisation, as the former CEO of HCD (1996-2006) explains:

"In the 1970s, there were a lot of squatters in London and they occupied many dwellings. In the 1980s, also, the housing cooperation increased with political support; there were lots of cooperative houses. Here there was the Hackney House Cooperative. This was a group that supported people who wanted to live in a cooperative house. Based on this experience, they thought that it would also be possible to develop business in a cooperative way. They asked local authority for a place to start businesses and received Bradbury Street, with the agreement to raise the funds to renew the entire building. The regeneration was funded with the Government money invested to increase the economic and social situation of suburban areas. This money was pushed into community organisations in order to stop conflicts." (Interview to former CEO, 2017).

The main HCD aim is supporting the community through the development of new cooperatives and social companies. It can improve local people's conditions because businesses can bring wealth if they are set up with social and mutual values. The focus is on the disadvantaged people of Hackney who cannot be helped simply with the traditional support provided by the state. Ethnic minorities and women are the main targets of HCD services. This is a Company Limited by Guarantees, it does not have a share capital, and from 2005 it is a Community Interest Company. Members of $\mathrm{HCD}$ can be people, other organisations and public authorities that support the aims of $\mathrm{HCD}^{3}$. The general assembly gathers all the members who elect the general council, which is also composed of representatives of other organisations:

- Six seats for local worker co-operatives, common ownership enterprises and small businesses representatives;

- Two seats for trade union organisations;

- Five seats for community and voluntary organisations;

- Two seats for employees of the company4.

Over the years, this strong relationship with the territory has influenced the HCD's services. The peculiarity of this organisation is the focus on the local communities' issues and the research on new solutions to tackle the social and economic problems of disadvantaged groups. HCD works within its community since 1982, and its services are in line with its mission.

3 The company acts of 1985 and 1989.

4 Ibidem. 
- Affordable business premises: HCD is the owner of 73 spaces in Hackney 5 . These include small offices, medium-sized workspaces, retail outlets and night time economy venues. These properties are in part under ownership of Hackney Council, such as the Bradbury Street and Beechwood Road buildings. The support for the economic growth of Hackney starts from the availability of workspaces for people who cannot afford the market price.

- Pioneering social enterprise in Hackney: this programme has the aim to support new co-operative and social enterprises. This service provides support in business planning, market analysis, design of products and services, change of management structure, conversion into a new legal structure as CIC or co-operatives, strategy for rapid economic growth, and preparation for trading in the first year.

- "English my way" and "Learn my way": these two programmes are set-up to help people acquire basic skills for their social integration. The aim of these is to enforce the knowledge of English for newcomers and the use of the internet and computer. These courses are clear examples of empowerment for disadvantaged people.

Alongside these projects, HCD has invested great funds and commitment in the regeneration of Gillet Square. HCD has received a mandate by LB Hackney to lead in utilising this public space for community benefit. This included the granting of a unique Permanent Entertainment Licence for the square, which allows responsive and flexible programming of the space for different purposes. Surrounded by Bradbury Street and Kingsland Road, this is not just a place, it is the reason why this company can be considered a good example of urban regeneration through community-led enterprises.

The history of this place is 25 years old. It began when the Hackney Council gave the building around the square to HCD with the agreement of an innovative renewal of the area.

- From 1982 to 1984, HCD received 300,000 GBP from English Partnership, a national program from DCLG for the renewal of under-developed areas, for the reestablishment of the building in Bradbury Street (that surrounds Gillet Square). This was the first headquarters of HCD and it is here that many businesses found a workspace with affordable rents.

- From 1994 to 1997, the Hackney based initiative obtained 2 million GBP, 70\% from public programs (City Challenge) and 30\% from the private sector for other works on the Bradbury Street building and other properties.

- In 1993, HCD commissioned to Collective Building Design the creation of a project for the re-development of the area around its headquarters.

- In 1998, after several local public consultations, Hackney Council's Regeneration Committee designed Gillett Street car park as the future town square for Dalston.

- In 1997-2000, additional 300,000 GBP came for the purchase of the market stalls installed on Gillet Square (Single Regeneration Budget).

\footnotetext{
Ranging from 100 to 1,550 sq. $\mathrm{ft}$.
} 
- In 1999, HCD installed ten market pod kiosks on the south side of the square.

- In 2001, the Gillet Square Partnership was formed as a development and management agency, it comprised Groundwork East London; The Vortex Jazz Club; London Borough of Hackney Planning, Leisure and Property Directorates; MacDonald Egan; Greater London Authority's Architecture and Urbanism Unit and Hawkins Brown.

- In 2003 Gillett Square was adopted as one of Mayor Livingstone's new urban spaces for London, which led to the involvement of the GLA's Architecture and Urbanism Unit in the Gillett Square partnership. This program was part of a major urban policy promoted by the Labour Mayor of London, which aims to improve the sustainable renewal of under-used spaces in many locations. HCD had supported this project through a mix of private and public funds. The majority of these resources were from national programs and European funds.

- In 2005, Dalston Culture House completed the norther side of the square.

- From 2003 to 2005, the work on the Dalston Culture House, which occupies the western side of Gillet Square, cost 1 million GBP; $60 \%$ of these were from the Neighbourhood Renewal Fund and European Regional Development Fund (ERDF); 40\% was from a private social bank (Triodos). The final cost for Gillet Square has been 1.6 million GBP subdivided between London City Hall (500,000 GBP), the national government (750,000 GBP) and Transport for London (350,000 GBP). These figures confirm Moulaert and Vicari Haddock's research results, the majority of the funds used for the urban regeneration projects in Europe were public, and this case is proof of that.

- In 2006, official inauguration of Gillet Square.

These numbers show how HCD supported this project over the years. These programs have represented a sustainable way for the purposes of this community enterprise. It promoted regeneration for the integration of a social mix of people (Punter, 2010). This is in line with the historical evolution of urban policies delineated in the previous paragraphs.

"Outline plans for the square were developed in the context of further public consultations and events organized by HCD and Groundwork through their local networks, membership of the Local Strategic Partnership and the Neighbourhood Forum. The plans for the square were well publicized in articles in the local press. The planning application for the square, in the name of the Gillett Square Partnership, was approved by LBH full planning committee in 2005, with no objections from the public." (www.gilletsquare.org.uk).

Since its launch, Gillet Square has suffered many problems related to drugs and alcohol abuse and anti-social behaviours due to many vulnerable people who used to live in the square before its renewal (A5cent, 2016). The negative impact of these phenomena led HCD to form the Join Action Group, which involves police, LB Hackney, residents, local businesses and services. This group has worked on the issue of anti-social behaviours in order to avoid them, not to exclude people from Gillet Square. Police have increased the presence of patrols in the square and Single Homeless Project has offered support to street drinkers. After this intervention, complaints decreased by $78 \%$. The HCD approach is that the problem is the behaviour not the individual person, HCD does not 
want to exclude anyone from the square (A5cent, 2016). The 2016 consultation confirms this sense of community safety in this place.

The role of the Gillet Square Action Group (GSAG) is not secondary for the success of Gillet Square. As explained above, the idea of wide involvement of local stakeholders has always been at the base of this project from the beginning. As the Creative Manager of Gillet Square for many years explains, the group is an important element in the development of the annual cultural program:

"In July 2014 HCD held an event called 'An Open Discussion on Gillett Square'. It provides a space in which anyone who wanted could bring their ideas and thoughts about the square and how it should work forward. We also asked one of the presenters who had a good relationship with some of the regular street drinkers to encourage them to attend. We did in fact have a really wide range of people attendingbusiness owners, residents, street drinkers, different ages, genders, and ethnicity. It was clear there was a lot of passion and willingness for the square to really work as a community asset and that a regular forum like this was needed." (Interview to Creative Manager Gillet Square, 2017).

GSAG is a free membership place for regular discussions on the cultural work in Gillet Square. Due to the mission of this project, regarding the involvement of all the citizens and groups in Dalston, a wide plethora of participants is very useful. During the first two years of activity, the group used to meet every two months, but after a while it became clear that a more frequent schedule was necessary. In the end of 2016, they decided to meet every month.

"The objectives of the Action Group were to bring out community resources, empower people, forge links and have community led events taking place in the square as a result - this has happened and still continues. The objective of the Gillett Square Project at large is to have a public space that works for all the community, is safe, comfortable; improves social cohesion; reduces isolation, and has a positive impact on people's health. The Action Group is one of the ways of meeting the objectives and also acts as ongoing evaluation, as people will say what things have worked or not worked, we also have a proactive reflection at the end of the year." (Interview to Creative Manager Gillet Square, 2017).

The work in partnership with many other organisations and groups in the neighbourhood has led HCD to base its cultural work in Gillet Square on input from a plethora of stakeholders. Consequently, the community enterprise has had the opportunity to assess its work also through the point of view of these partners. In addition, the independent evaluation from A5cent has given more emphasis to the HCD commitment to Dalston. People appreciate the time spend at Gillet Square during the organised activities, the Games Days report $2015^{6}$ demonstrates that parents and children developed new social skills and enhanced interactions with other families. Super Dad Games Days report shows that $98 \%$ of child respondents assessed the time spent together with their fathers was qualitatively better than the game time during other days. The $90 \%$ of fathers agreed they had learned something new about their children. The majority of the interviewees (32 out of 45 people) confirmed that these occasions improved their social interrelations and decreased their feelings of isolation.

6 Organised by Universal Board Games Charity London. 
HCD's Stories from Gillet Square (2014) found that people consider this project a place where everyone can feel part of a community. Activities are inclusive and the free entrance allows everyone to be engaged. There is a good grade of social and ethnic mix. The same results were recorded during the Something Different Festival (2014) and Vortex Outdoors Festival (2014). The Hackney Circle program is another of HCD's partners. It organises different events for the promotion of socialisation in the borough, with a particular focus on older people. The operators of this scheme reported in the 2015 evaluation that older people involved in Gillet Square activities have had a positive perception of this place.

\section{Discussion}

The work with the community is a consequence of the HCD's values. As the former CEO explains, the cooperative movement has always promoted the collaboration among people and organisations for the community's benefit. These intrinsic values, due to its background in the London cooperative movement, and the directives from the programs promoted by the British governments and the European Union influenced HCD's work. The majority of the funds for the project were public: European Regional Development Fund (ERDF) selected it as one of the ten pilot projects for London by the Greater London Authority's (GLA) Urbanism and Architecture Panel (AAUU). Gillet Square was also funded by the Mayor Livingstone's new urban spaces for London program, the English Partnership program, City Challenge program and Single Regeneration Budget. This point highlights how the evolution of urban policies has found an important match with the work of local community-led organisations and enterprises. This coalition of funds, objectives and intentions has steered the Gillet Square project. National and European policies had the capacity to foster a new way for the urban regeneration of inner cities underpinned by social innovation; alongside, the mutual influence between government and civil society, as in the case of Locality, has shaped these urban policies. The recognition of these local actors and the discussion with the policy makers is the key element of the top-down level. On the bottom-up, the organisations can strengthen their work in territories through access to resources which support their missions for communities.

The network built by HCD over the years is a strategic asset for its work because it allows the company to recognise and improve the potential in this area. A clear outcome is the involvement of many citizens, who are part of other networks, and collaborate with HCD. The engagement of these people is possible due to the relationships and competencies of the HCD's partners, which work on different targets such as families, older people and ethnic groups. The partnership with the Hackney Council is also an important connection. First, it has provided the HCD with the building in Bradbury Street and the former car park where now exist Gillet Square, HCD offices and many other businesses supported by the CIC. Secondly, the HCD has built a professional relationship with the Hackney Council that allows the two actors to trust each other and implement a local social strategy for the Dalston area. This is a case of mutual exchange between the third 
sector and a local policy maker. The first operates every day in the territory with many people from disadvantaged situations (immigrants without communication skills, new entrepreneurs, ethnic minorities, private businesses, street drinkers, elderly people, etc.). The second has the task of implementing policies for the wellbeing of citizens. This partnership appears as an outcome of top-down policies that promote a more direct collaboration between public and private sectors; the public authorities support private organisations and coordinate their efforts in the neighbourhoods, meanwhile, the third sector works everyday with local residents in order to understand their needs and promote new projects. These connections permit the regeneration of local assets because the public sector supports private organisations not only with an innovative policy framework but also with asset transfer. There is a double benefit: social businesses and organisations do not have to build or rent by themselves their own offices and have a drastic reduction on their annual budgets; on the other hand, the public authorities, which have to deal with a strong reduction in public resources, can realise a sustainable and social regeneration of many assets in their purview.

The emphasis on the network inside the community is not a marginal aspect in this analysis. As Kisby (2010) points out, urban renewal projects for social inclusion are possible with the engagement of local stakeholders for a real understanding of contexts, social issues and people's potential. These connections, that represent the social capital of each organisation, are a key point in the analysis of community enterprises. This social capital allows for calibrating the services to fit the local needs and to drive the use of community assets in a direction that can support local socio-economic development. Moreover, community-led enterprises can harness the social capital present in a community and use it to generate positive outcomes (Bailey, 2012; Bailey, Kleinhans and Lindbergh, 2018). The ability to catch the implicit knowledge of local people enables the community-led enterprises to represent them in other forums.

HCD has regular meetings and collaborations with local stakeholders, in particular the Hackney Council for a general monitoring of the Gillet Square project, security issues, and social enterprise development. This mutual support fosters more inclusion, reduction of isolation, as assessed by its partners, and people's involvement in Dalston revitalisation.

\section{Conclusion}

Community Interest Companies are playing an important role in urban regeneration (Bailey, 2012; Tricarico, 2014; Bianchi, 2016) but their impact is explainable especially through the intense work in communities. Civil engagement and the presence of community-led enterprises for the provision of services and, in general, a more inclusive approach, rather than one that is predominately market-oriented, are a key element for renewal processes that foster social innovation. As Vicari Haddock and Moulaert (2009) underline in their analysis of urban regeneration patterns in Europe, the renovation of many former abandoned areas does not include a real social inclusion of local people, on the contrary it creates new zones for new people. A clear example are the cultural-centres 
projects, around which the former areas have become fashionable and elegant neighbourhoods where the costs of new houses are higher than before the requalification. On one hand, it means that it is a success for planners and local governments, as many inner cities are now wonderful places with new houses, services and businesses. On the other hand, the privatisation processes have brought the displacement of low-income people from their areas due to the increase in the cost of living and house prices. These projects, theoretically, create new job positions but researchers underline many biases in these results. The increase of the construction industry is inevitable, but temporary. The employment generated is dual: on one hand, high-qualified jobs have been created in the field of services and support for businesses. On the other hand, many non-qualified jobs have been created in traditional fields as restorations, security and cleaning services, which have the lowest wages. This solution cannot satisfy the needs of many inner cities where the levels of education are low and the social needs are huge.

Gillet Square and HCD's work can generate important social outputs in the regeneration process because they combine the top-down request for a more inclusive and participative process with the intense bottom-up work with the community. The results clearly indicate how Gillet Square is socially innovative and generates benefits for the community. This case study can represent a good practice for other community organisations looking to implement such efforts and can contribute in the academic debate by providing the main features of a 35 years old project deeply rooted in London which manages key relations with local stakeholders. This paper confirms the main theories regarding participative urban regeneration processes and demonstrates the relevance of policy indications on social private sector involvement for planning and re-development of urban areas.

A future need of research that emerges from this study could be the assessment of the indirect consequences that the Gillet Square project can have on the Dalston area. The cultural programs call many people from the Hackney borough and from London in general. This attraction brings customers for the local small businesses, which in part are also HCD's tenants, so we can consider this a good output of the project. Nevertheless, this good reputation of Hackney as an artistic and alternative neighbourhood is bringing attention that is fostering gentrification dynamics, as explained above. Further research could investigate the role of Gillet Square in the construction of Hackney's reputation because if it is true that HCD manages its own properties with social objectives, it is important to understand the impact on the properties around the square in terms of value growth.

This must be a caveat for all the community organisations, they can fight against a neoliberal system and find in the cooperative community-led model a possibility; but they still remain inside the system and these organisations are in many cases enterprises, which means that they need customers. I agree with the perspective that sustains that these cultural initiatives can bring people from other places inside neighbourhoods, which have been considered in a bad light for years. The community development movement must keep in mind Prof. Florida's thesis (2002) on the creative class, which might bring wealth, but it triggers process of cost increase and former dwellers' 
displacement. A good community organisation works with a community, not only in a community. Sharing aims, objectives, resources, and a vision of the neighbourhood is strategic for building real impact in community. Otherwise, an organisation that is not able to work in synergy with other partners and stakeholders could just steer its own project on the neighbourhood ignoring what can be alternative interventions and solutions, fostering a closed-mind vision that can only improve the subject's self-interest.

\section{References}

A5scend. (2016, September). The Gillet Squared Project. An Indipendent Review. A5scend.

Bailey, N. (2012). The role, organisation and contribution of community enterprise to urban regeneration policy in the UK. Progress in Planning, 77: 1-35. DOI: https://doi.org/10.1016/j.progress.2011.11.001.

Bailey, N., Kleinhans, R. \& Lindbergh, J. (2018). The Implications of Schumpeter's Theories of Innovation for the Role, Organisation and Impact of Community-Based Social Enterprise in Three European Countries. Journal of Entrepreneurial and Organisational Diversity, 7(1): 14-36. DOI: http://dx.doi.org/10.5947/jeod.2018.002.

Barton, H., Grant, M. \& Guise, R. (2003). Shaping Neighbourhoods: A Guide for Health, Sustainability and Vitality. Oxford, UK: Taylor \& Francis.

Bianchi, M. (2016). How communities can regenerate urban context. The case study of Hackney Co-operative Developments. Euricse Working Paper Series, n. 87/16. Trento: Euricse. Available at: https://www.euricse.eu/ it/publications/wp-how-communities-can-regenerate-urban-contexts-the-case-study-of-hackney-co-operativedevelopment/ [Accessed: January 2019].

Colquhoun, I. (1995). Urban Regeneration: An International Perspective. London: B.T. Batsford Limited.

Couch, C., Fraser, C. \& Percy, S. (2003). Urban Regeneration in Europe. Oxford, UK: Blackwell Science. DOI: https:// doi.org/10.1002/9780470690604.

DCLG (2007). Making assets work: The Quirk review of community management and ownership of public assets. London: Department for Communities and Local Government. https://webarchive.nationalarchives.gov.uk/20120920045030/http://www.communities.gov.uk/documents/ communities/pdf/321083.pdf

DCLG (2011). Regeneration to enable growth: What Government is doing in support of communityled regeneration. London: Department for Communities and Local Government. https://webarchive.nationalarchives.gov.uk/20120919220828/http://www.communities.gov.uk/documents/ regeneration/pdf/1830137.pdf

DCLG. (2012). Community Right to Bid: Non-statutory advice note for local authorities. Department for Communities and Local Government - London https://www.gov.uk/government/publications/community-right-to-bid-nonstatutory-advice-note-for-local-authorities

Deas, I. (2013). Towards Post-political Consensus in Urban Policy? Localism and the Emerging Agenda for Regeneration under the Cameron Government, Planning Practice \& Research, 28(1): 65-82. DOI: https://doi.org/10.1080/0 2697459.2012.699228.

Eizaguirre, S. \& Parés, M. (2018). Communities making social change from below. Social innovation and democratic leadership in two disenfranchised neighbourhoods in Barcelona, Urban Research \& Practice. DOI: https://doi.or $\mathrm{g} / 10.1080 / 17535069.2018 .1426782$.

Fenton, A. (2016). Gentrification in London: a progress report 2001-2013. Case 195/16. Centre for Analysis of Social Exclusion. London School of Economics. 
Florida, R. (2002). The Rise of the Creative Class: And how It's Transforming Work, Leisure, Community and Everyday Life. New York: Hazard Press.

Frey, H. (1999). Designing the City: Towards a More Sustainable Urban Form. London ; New York: Taylor \& Francis.

Glass, R. \& Westergaard, J. (1965). London's housing needs: statement of evidence to the Committee on Housing in Greater London. London: Committee on Housing in Greater London, Centre for Urban Studies, University College.

Hackney Council (2007). Social Space. A strategy for parks in Hackney 2008-2013. London: Hackney Council.

Hackney Council (2015). Local Economy Profile. London: Hackney Council.

Hackney Council (2017). A Profile of Hackney, its People and Place. London: Hackney Council. DOI: https://doi. org/10.1071/PVv2017n190p45.

Home, R.K. (2013). Inner City Regeneration. London \& New York: Routledge. DOI: https://doi. org/10.4324/9781315889085.

Jones, P. \& Evans, J. (2008). Urban Regeneration in the UK. Available at: http://sk.sagepub.com/books/urbanregeneration-in-the-uk

Kisby, B. (2010). The Big Society: Power to the People? The Political Quarterly, 81(4): 484-491. DOI: https://doi. org/10.1111/j.1467-923X.2010.02133.x.

Lawless, P. (2011). Big Society and community: lessons from the 1998-2011 New Deal for Communities Programme in England, People, Place and Policy, 5(2), 55-64. DOI: https://doi.org/10.3351/ppp.0005.0002.0002.

Moulaert, F., Swyngedouw, E., Martinelli, F. \& Gonzalez, S. (2010). Canneighbourhoods save the city? Community development and social innovation. London \& New York: Routledge. DOI: https://doi.org/10.4324/9780203849132.

Moulaert, F. (2013). The International Handbook on Social Innovation: Collective Action, Social Learning and Transdisciplinary Research. Chelthenham UK; Northampton, MA: Edward Elgar. DOI: https://doi.org/10.4337/9781849809993.

Moulaert, F., Rodriguez, A. \& Swyngedouw, E. (2003). The Globalized City. Economic Restructuring and Social Polarization in European Cities. Oxford: Oxford University Press.

Parés, M., Ospina, S. \& Subirats, J. (2017). Social Innovation and Democratic Leadership Communities and Social Change from Below. Cheltenham, UK; Northampton, MA: Edward Elgar Publishing. DOI: https://doi. org/10.4337/9781785367885.

Pearce, J. (2003). Social Enterprise in Anytown. London: Calouste Gulbenkian Foundation.

Peredo, A.M., \& Chrisman, J.J. (2006). Toward a theory of community-based enterprise, Academy of Management Review, 31(2): 309-328. DOI: https://doi.org/10.5465/amr.2006.20208683.

Porter, L. \& Shaw, K. (2013). Whose Urban Renaissance? An international comparison of urban regeneration strategies. London: Routledge.

Punter, J. (2010). Urban Design and the British Urban Renaissance. London: Routledge. DOI: https://doi. org/10.4324/9780203869208.

Roberts, P., Sykes, H. \& Granger, R. (2016). Urban Regeneration. London: SAGE. DOI: https://doi. org/10.4135/9781473921788.

Swyngedouw, E., Moulaert, F. \& Rodriguez, A. (2012). Neoliberal Urbanization in Europe: Large-Scale Urban development projects and the new Urban Policy. In: Brenner, N. \& Nik, T. (Eds.), Spaces of Neoliberalism: Urban Restructuring in North America and Western Europe, pp. 194-229. DOI: https://doi.org/10.1002/9781444397499.ch9.

Tallon, A. (2010). Urban regeneration in the UK. London: Routledge.

Tricarico, L. (2014). Imprese di Comunità nelle Politiche di Rigenerazione Urbana: Definire ed Inquadrare il Contesto Italiano, Euricse Working Paper Series, n. 68/14. Trento: Euricse: Available at: https://www.euricse.eu/publications/ wp-68-14-imprese-di-comunita-nelle-politiche-di-rigenerazione-urbana-definire-ed-inquadrare-il-contestoitaliano-2/ [Accessed: January 2018] 
Tricarico, L. \& Zandonai, F. (2018). Local Italy. I domini del 'settore comunità in Italia. Milano: Fondazione Giangiacomo Feltrinelli.

Universal Board Games (2015). Games Days Report. London: Universal Board Games.

Varady, D., Kleinhans, R. \& Van Ham, M. (2015). Community Entrepreneurship in Deprived Neighbourhoods: Comparing UK Community Enterprise with US Community Development Corporations, IZA discussion paper, n. 8777.

Verhage, R. (2005). Renewing urban renewal in France, the UK and the Netherlands: Introduction, Journal of Housing and the Built Environment, 20(3): 215-227. DOI: https://doi.org/10.1007/s10901-005-9015-4.

Vicari Haddock, S. \& Moulaert, F. (2009). Rigenerare la città: pratiche di innovazione sociale nelle città europee. Bologna: Il Mulino. 